\title{
Elemental segregation during resistance spot welding of boron containing advanced high strength steels
}

\author{
Murugaiyan Amirthalingam $1,4,5$ - E. M. van der $\mathrm{Aa}^{2}$ - C. Kwakernaak ${ }^{3}$. \\ M. J. M. Hermans ${ }^{4}$. I. M. Richardson ${ }^{4}$
}

Received: 14 August 2014 / Accepted: 21 May 2015 / Published online: 1 July 2015

(C) The Author(s) 2015. This article is published with open access at Springerlink.com

\begin{abstract}
The partitioning behaviour of carbon, phosphorous and boron during the solidification of a resistance spot weld pool was studied using experimental simulations and a phase field model. Steels with varying carbon, phosphorous and boron contents were designed and subjected to a range of resistant spot welding thermal cycles. Mechanical properties were evaluated by hardness and cross tension tests and correlated with the weld microstructure. Phase field modelling results and experimental predictions show that the phosphorus concentration in the last area in the weld pool to solidify can reach about $0.38 \mathrm{wt} \%$ for a steel with a bulk concentration of $0.08 \mathrm{wt} \%$. Elemental analysis indicates that in the absence of boron, the grain boundaries of
\end{abstract}

Doc. IIW-2563, recommended for publication by Commission II "Arc Welding and Filler Metals".

Murugaiyan Amirthalingam

m.amirthalingam@tudelft.nl

1 Foundation for Fundamental Research on Matter (FOM), Delft, The Netherlands

2 Tata Steel, P.O. Box. 10000, 1970 CA, IJmuiden, The Netherlands

3 Surfaces and Interfaces, Material Science and Engineering, Delft University of Technology, Mekelweg 2, 2628CD, Delft, The Netherlands

4 Metals Processing, Microstructure and Properties (MPMP), Material Science and Engineering, Delft University of Technology, Mekelweg 2, 2628CD, Delft, The Netherlands

5 Formerly with Materials Innovation Institute (M2i), P.O.Box 5008, 2600GA, Delft, The Netherlands columnar grains in the weld pool are decorated with phosphorous. As a result, a complete interface failure occurs during cross tension testing. With the addition of boron, apart from an increase in weld strength and plug diameter, the failure mode switches to a complete plug mode, resulting from the phosphorous depletion at the grain/inter-phase boundaries.

Keywords (IIW Thesaurus) Resistance spot welding • Segregation · B additions · Low alloy steels · Mathematical models $\cdot$ Microstructure

\section{Introduction}

The mechanical properties of advanced high-strength steels (AHSS) for automotive applications are sensitive to their multi-phase microstructures, which are carefully designed and realised by selection of the composition and production route [1]. A combination of alloying elements and complex heat treatment generates microstructures with required amounts, size and distribution of phases. Unfortunately, the thermal cycles of welding processes destroy the original microstructure. In addition, alloying elements present in the steel can significantly affect the weldability, for example, by forming complex inclusions in the fusion zone and stabilising unsolicited phases in the heataffected zone [2]. About 0.01 to $0.1 \mathrm{wt} \%$ of phosphorous is added in low-alloyed steels mainly as a solid solution strengthener to achieve the required mechanical properties. In some AHSS such as transformation-induced plasticity (TRIP) and quench and partitioning (Q\&P) steels, phosphorous is added to (i) improve the strength by solid solution strengthening and (ii) reduce the amount of silicon in TRIP and $\mathrm{Q} \& \mathrm{P}$ steels in order to improve the galvanisability 
Table 1 Composition of the steels under investigation. Steels also contain $0.3 \mathrm{Si}, 2.2 \mathrm{Mn}, 0.65 \mathrm{Cr}(\mathrm{wt} \%)$ apart from $\mathrm{C}, \mathrm{P}$ and $\mathrm{B}$

\begin{tabular}{llll}
\hline Elements, wt $\%$ & C & P & B \\
\hline Steel-CP & 0.07 & 0.08 & - \\
Steel-2CP & 0.14 & 0.08 & - \\
Steel-CPB & 0.07 & 0.08 & 0.0027 \\
\hline
\end{tabular}

[3-6]. Phosphorous is also known to suppress the formation of cementite and thereby increase the amount of austenite retained at room temperature [3]. However, the segregation of phosphorous to the grain boundaries during welding leads to embrittlement [7,8]. The formation of complex phosphides affects the amount of substitutional elements in solid solution in the matrix and thereby the hardenability of the steels [9-11]. The addition of boron to phosphorous containing steels is known to improve grain boundary cohesion by reducing phosphorous segregation, thereby reducing embrittlement $[12,13]$. Boron also improves the hardenability of steels, mainly by retarding the nucleation of polygonal ferrite at austenite grain boundaries [14-16]. Babu et al. [14] report different weld sizes for two steels with nominally identical compositions, one containing 5 ppm boron by weight and the other $20-40 \mathrm{ppm}$ boron by weight. It was suggested that the higher boron content steel resulted in a larger weld because it exhibited a higher contact resistance during resistance seam welding. A new generation of borontreated automotive steels are currently of interest because they can be hot stamped and subsequently quenched to produce a martensitic structure with high strength, typically in the range of 900 to $1200 \mathrm{MPa}$ [17]. Studies on the effect of boron content on the weldability of high-strength steels indicate that increasing boron concentration above $100 \mathrm{ppm}$ in the weld metal results in cracking [18]. Therefore, understanding the effect of boron on inter-dendritic and grain boundary segregation of carbon and phosphorous during welding is necessary for the development of phosphorous and boron-containing AHSS.

Phase field modelling has been used to simulate microstructures during various metallurgical processes such as solid-state transformations [19-24] and solidification [25-27]. Steinbach et al. proposed a multi-phase field model to simulate multi-phase microstructures $[28,29]$ and was used to simulate solidification during continuous casting of steel grades [30].

In this work, steels with varying carbon, phosphorous and boron contents were designed and subjected to resistance spot welding thermal-mechanical cycles. Solidification of the weld pool under continuous cooling from $1800 \mathrm{~K}$ is simulated using a phase field code Micress ${ }^{\circledR}[28,29]$ directly coupled to thermodynamic (TCFE6) and mobility databases (MOB2). The partitioning behaviour of carbon, phosphorous and boron during the solidification of weld pools subjected to various weld thermal cycles has been studied using electron probe microanalysis (EPMA) and compared with the results of developed phase field model. Mechanical properties of the welds were evaluated by hardness and cross tension tests and correlated with weld microstructure.

\section{Experimental procedure}

Boron- and phosphorous-containing steels (Table 1) were designed, cast and rolled on a laboratory scale to a thickness of $1.5 \mathrm{~mm}$. Apart from carbon, phosphorous and boron, these steel samples also contain $0.3 \mathrm{Si}, 2.2 \mathrm{Mn}, 0.65 \mathrm{Cr}$ (wt\%). The composition of the steels (Table 1) used in this investigation was designed based on a typical dual phase (DP1000) chemistry [31]. The phosphorous concentration of the steels $(0.08 \mathrm{wt} \%)$ was however higher than commercially produced DP1000 chemistries, where it is generally within 0.005 to $0.02 \mathrm{wt} \%$. The steels with higher amount of phosphorous were designed to investigate the possibilities of increasing the concentration without affecting weldability and also to study the effect of boron addition on the segregation behaviour of phosphorous. Steel-CP and Steel-CPB contained $0.07 \mathrm{wt} \%$ and Steel-2CP contained $0.14 \mathrm{wt} \%$ of carbon, respectively.

Resistant spot welding was carried out on a Schlattes ${ }^{\mathrm{TM}}$ $50-\mathrm{Hz} \mathrm{A} / \mathrm{C}$ spot welding machine using $\mathrm{F} 16 \times 5.5$ electrodes with a holding force of $4.5 \mathrm{kN}$. Welding parameters are summarised in Table 2. I(min) is the weld current needed to produce a $4 \sqrt{t}$ weld nugget diameter, where $t$ is the plate thickness $(1.5 \mathrm{~mm})$ and $\mathrm{I}(\max )$ is the highest current before expulsion (splashing) occurred for each sample. Welding parameters shown in Table 2 were used to generate

Table 2 Resistance welding parameters. I(min) is the weld current needed to produce a $4 \sqrt{t}$ weld diameter, where $t$ is the plate thickness (1.5 mm) and $\mathrm{I}(\max )$ is the highest current before expulsion (splashing). One cycle is $20 \mathrm{~ms}$

\begin{tabular}{llllll}
\hline & Squeeze time in cycles & Weld time in cycles & Hold time in cycles & $\mathrm{I}(\mathrm{min}), \mathrm{kA}$ & $\mathrm{I}(\mathrm{max}), \mathrm{kA}$ \\
\hline Steel-CP & 25 & 17 & 15 & 5.84 & 7.25 \\
Steel-2CP & 25 & 17 & 15 & 5.6 & 7.2 \\
Steel-CPB & 25 & 17 & 15 & 5.72 & 7.85 \\
\hline
\end{tabular}




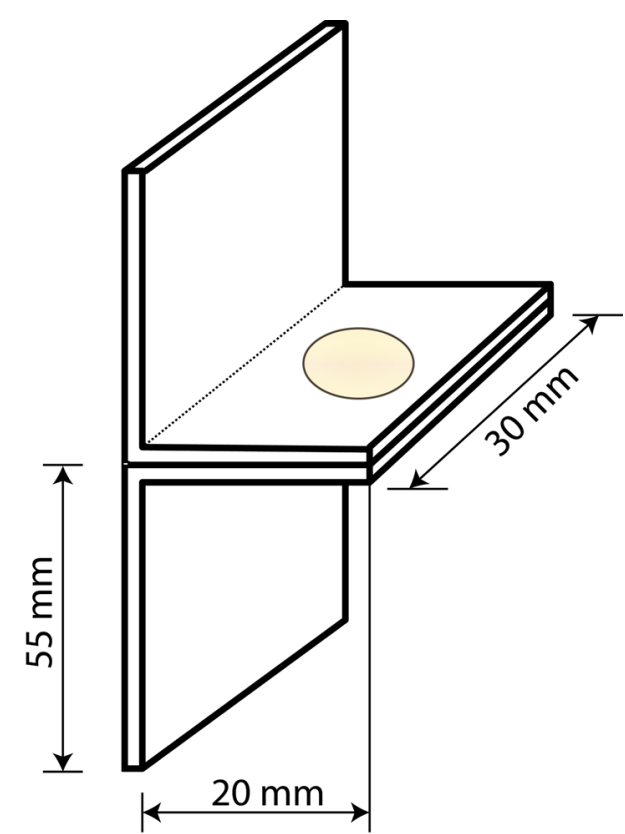

(a) $L$ shaped specimen for tensile peel tests. The typical spot sizes are given in table 5 .

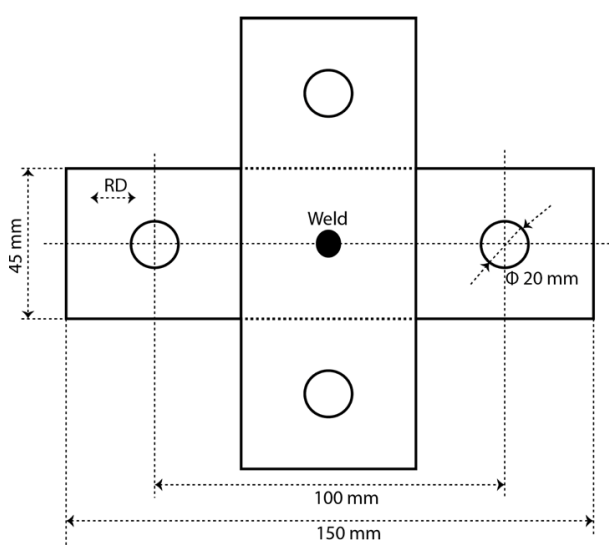

(b) Cross tension specimens (CTS)

Fig. 1 a Shows the samples used to generate weld growth curves and b shows the cross tension test samples

weld nuggets for microstructural, elemental analyses and hardness measurements.

The weld growth curve was constructed using tensile peel specimens (LTS) with an $L$-shaped configuration as shown in Fig. 1a. After the tensile peel testing (LTS), failure modes of the welds were examined visually and by optical microscopy. The mechanical strength was evaluated using cross tension specimens (CTS), with dimensions shown in Fig. $1 b$. The testing procedure and documentation guidelines can be found elsewhere [32]. During the weld growth analysis, both the weld nugget diameter and the plug diameter after the LTS and CTS testing were measured. From these, the plug ratio, the ratio between plug diameter and the weld nugget diameter was calculated. A plug ratio of $0 \%$ indicated a full interface failure, and at $100 \%$, the weld was intact after the testing.

Vickers hardness measurements with a load of $200 \mathrm{~g}$ were made to examine the hardness variations across the width of the spot-welded samples.

Samples for microscopy analyses were prepared after etching the polished samples with a $4 \%$ Nital solution for $5 \mathrm{~s}$. Optical microscopy analysis was carried out using an Olympus BX60M ${ }^{\mathrm{TM}}$ optical microscope equipped with image capturing and analysis software analySIS ${ }^{\mathrm{TM}}$. Scanning electron microscopy (SEM) was performed using a JEOL JSM 6500FTM_field emission gun (FEG). EPMA was carried out to analyse elemental distributions in the fusion zones of resistance spot-welded samples. The measurements were performed in a JEOL JXA 8900R microprobe using an electron beam with an energy of $10 \mathrm{keV}$ and a beam current of $200 \mathrm{nA}$ employing wavelength dispersive spectrometry (WDS). The composition at each analysis location was determined using the X-ray intensities of the constituent elements after background correction relative to the corresponding intensities of reference materials. The intensity ratios were processed with a matrix correction program CITZAF [33]. The backgrounds of the light elements $\mathrm{B}$ and $\mathrm{C}$ were measured on the spectral line wavelength position using a pure $\mathrm{Fe}$ standard. Each analysis location was decontaminated using an air jet during the measurement. The points of analysis were located along a line with increments of $5 \mu \mathrm{m}$ and involved the elements B, C and $\mathrm{P}$. The energy of the spectral lines, detection limits and counting errors are given in Table 3.

\section{Phase field simulation conditions}

Elemental partitioning behaviour during solidification was studied using the multi-phase phase field code MICRESS ${ }^{\circledR}$, which is based on the work of Steinbach et al. [28, 29].
Table 3 Energy of the spectral lines, detection limit and counting error of electron probe microanalysis (EPMA) measurement

\begin{tabular}{llll}
\hline Element, X-ray line & Energy, keV & Detection limit, ppm & Counting error, wt $\%$ \\
\hline Boron, $\mathrm{K}_{\alpha}$ & 0.185 & 50 & 0.02 \\
Carbon, $\mathrm{K}_{\alpha}$ & 0.282 & 100 & 0.02 \\
Phosphorous, $\mathrm{K}_{\alpha}$ & 2.013 & 30 & 0.01 \\
\hline
\end{tabular}


Table 4 Energy parameters used in the phase field simulation

\begin{tabular}{llll}
\hline Parameters & $L: \alpha$ & $L: \gamma$ & $\alpha: \gamma$ \\
\hline Surface energy, $\times 10^{-5} \mathrm{~J} \mathrm{~cm}^{-2}$ & 1.6 & 1.6 & 50 \\
Kinetic coefficient $(\mu), \times 10^{-3} \mathrm{~J} \mathrm{~s} \mathrm{~cm}^{-4}$ & 7.3 & 7.3 & 1 \\
Static anisotropy coefficient & 0.5 & 0.5 & - \\
Kinetic anisotropy coefficient & 0.3 & 0.3 & - \\
\hline
\end{tabular}

The solidification microstructures were simulated using this code while continuously cooling the liquid of the compositions mentioned in Table 1. Simulations were carried out on a two-dimensional $400 \times 400$ grid with a grid spacing of $2 \mu \mathrm{m}$. The phase field code was coupled with the thermodynamic software Thermo-Calc to obtain the equilibrium phase boundaries. The mobility data was directly obtained from the MOB2 database of Thermo-Calc. The energy parameters used in this simulation are shown in Table 4. The system was allowed to cool from $1800 \mathrm{~K}$ at the rate $1 \mathrm{~K} \mathrm{~s}^{-1}$ until the solidification was completed. At $1800 \mathrm{~K}$, the composition of the liquid was assumed to be homogeneous and a nuclei of $\delta$-ferrite was placed at the bottom left corner of the system. During the course of solidification, the system was set to undergo a peritectic reaction based on the local thermodynamic and chemical conditions by nucleating austenite at random positions on the interface. In order to simplify the calculations, only carbon, phosphorous and boron were allowed to diffuse and vary during solidification. However, while calculating equilibrium phase boundaries, ortho-equilibrium was assumed. Temperature-dependent thermodynamic and mobility data were updated at every second (therefore at every $\mathrm{K}$ of undercooling) while cooling from $1800 \mathrm{~K}$.

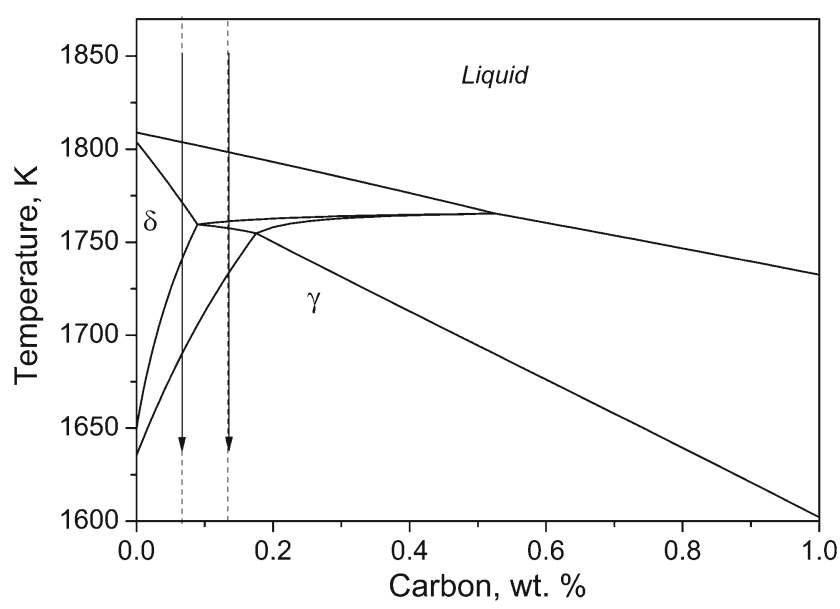

Fig. 2 Quasi-binary phase diagram of the steels under investigation, showing the solidification phase boundaries

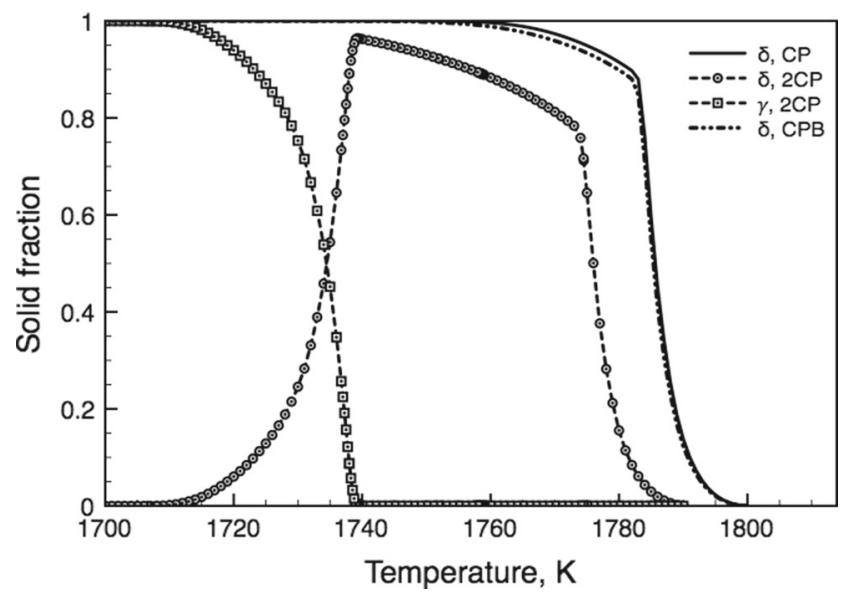

Fig. 3 Solid fraction during the solidification of the steels. Steel2CP shows a peritectic reaction, whereas the liquids of Steel-CP and Steel-CPB completely solidify to $\delta$-ferrite ( $\delta$ denotes $\delta$-ferrite and $\gamma$ is austenite)

\section{Results}

The quasi-binary phase diagram of the steels used in this work is shown in Fig. 2. The arrows indicate the phase regions involved in the solidification of liquid during cooling from $1850 \mathrm{~K}$. In Steel-CP and Steel-CPB, the liquid starts to solidify into $\delta$-ferrite initially and then the system enters into a complete ferritic region. The solidified $\delta$-ferrite subsequently transforms into austenite and the system becomes completely austenitic when the temperature reaches $1693 \mathrm{~K}$ under equilibrium conditions. In Steel-2CP, austenite starts to form from the liquid and the $\delta$-ferrite by a peritectic reaction starting from $1765 \mathrm{~K}$. Steel-2CP becomes completely austenitic at $1738 \mathrm{~K}$ under equilibrium conditions.

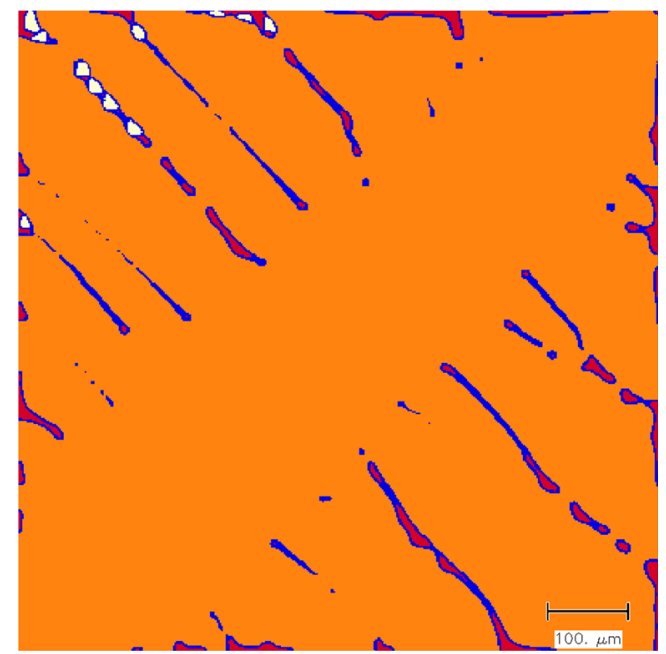

Fig. 4 Microstructure showing peritectic reaction in Steel-2CP at $1738 \mathrm{~K}$, showing $\delta$-ferrite (orange), austenite (white), liquid (red) and interface boundaries (blue) 


\subsection{Elemental segregation during solidification}

The carbon and phosphorous partitioning behaviour during the solidification of the steels (Table 1) was simulated using phase field modelling. In this simulation, liquid steels were cooled from $1800 \mathrm{~K}$ at a cooling rate of $1 \mathrm{~K} \mathrm{~s}^{-1}$, until the end of solidification. Figure 3 shows the solid fraction evolutions of steels while cooling from $1800 \mathrm{~K}$. Steel-CP and Steel-CPB showed a similar solidification behaviour during the initial stages of solidification. Upon further cooling below $1790 \mathrm{~K}$, Steel-CPB showed a slight sluggishness in solidification. The onset of solidification ( $1 \mathrm{vol} . \%$ of solid formation) in Steel-2CP was observed at lower temperature $(1787 \mathrm{~K})$ than that of Steel-CP and Steel-CPB (1796 K). In Steel-2CP, while cooling at $1 \mathrm{~K} \mathrm{~s}^{-1}$, a peritectic reaction was found to occur at $1738 \mathrm{~K}$ (Fig. 4), whereas liquids of Steel-CP and Steel-CPB solidified completely to $\delta$-ferrite before the completion of solidification.

The phase field simulations of microstructural evolution and corresponding elemental distributions during solidification of the steels are shown in Figs. 5, 6 and 7. A clear evidence of carbon and phosphorous partitioning is shown during the solidification. While cooling at $1 \mathrm{~K} \mathrm{~s}^{-1}$, the liquid of Steel-CP completely solidifies at $1764 \mathrm{~K}$ and Steel-CPB at 1758 K. Just before the completion of the solidification, the carbon in liquid of both $\mathrm{CP}$ and $\mathrm{CPB}$ steels increases to as high as $0.45 \mathrm{wt} \%$, whereas the bulk carbon content of these steels is only $0.07 \mathrm{wt} \%$. Similar enrichment of phosphorous is also found during the final stages of solidification. However, due to the addition

Fig. 5 a-d First row shows the evolution of the solidification microstructure of Steel-CP, during cooling from $1800 \mathrm{~K}$ at a rate of $1 \mathrm{~K} \mathrm{~s}^{-1}$ where the red colour indicates liquid, yellow denotes $\delta$-ferrite and the dendritic boundaries are shown in blue. e-l The second and third row denote the corresponding carbon and phosphorous distribution. The scale bars show concentration of the elements in weight percentage

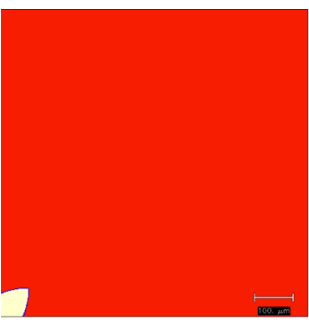

(a) at $1797 \mathrm{~K}$

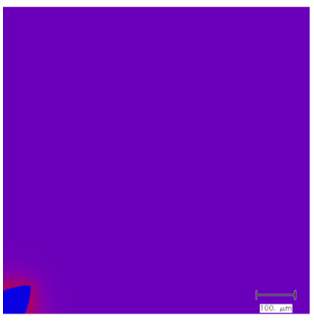

(e) at $1797 \mathrm{~K}$

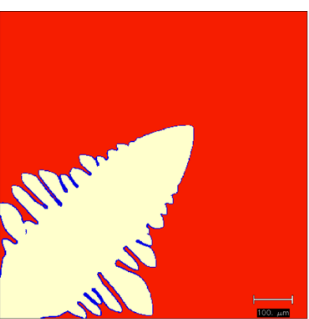

(b) at $1788 \mathrm{~K}$

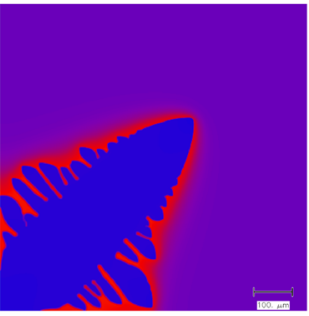

(f) at $1788 \mathrm{~K}$

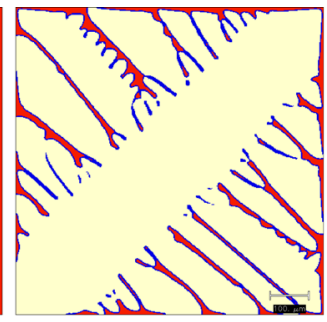

(c) at $1782 \mathrm{~K}$

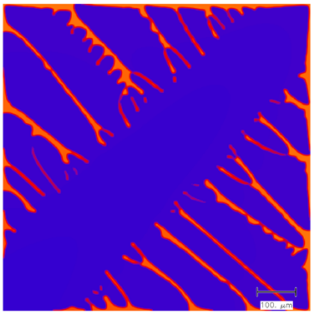

(g) at $1782 \mathrm{~K}$

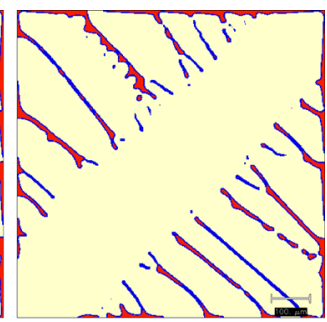

(d) at $1778 \mathrm{~K}$

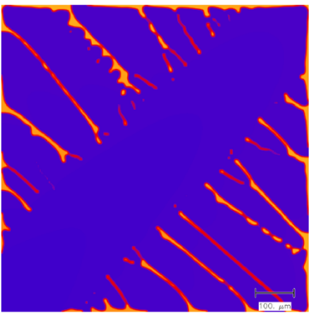

(h) at $1778 \mathrm{~K}$

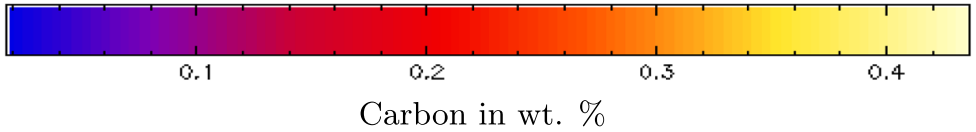

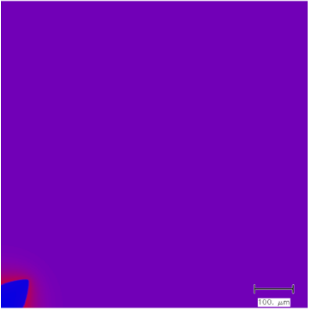

(i) at $1797 \mathrm{~K}$

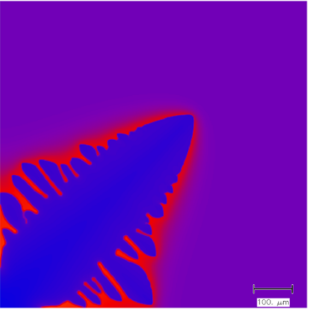

(j) at $1788 \mathrm{~K}$

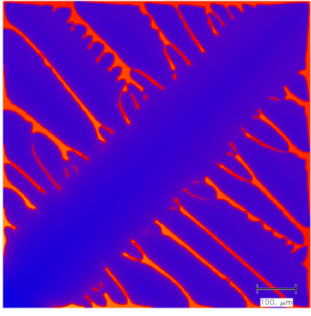

(k) atl1782 K

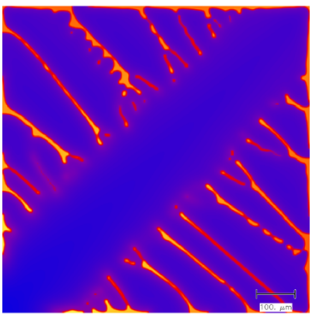

(l) at $1778 \mathrm{~K}$

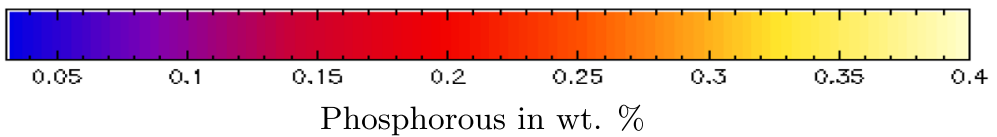


Fig. 6 a-d First row shows the evolution of the solidification microstructure of Steel-2CP, during cooling from $1800 \mathrm{~K}$ at a rate of $1 \mathrm{~K} \mathrm{~s}^{-1}$ where the red colour indicates liquid, orange denotes $\delta$-ferrite, white is austenite and the dendritic boundaries are shown in blue. e-l The second and third row denotes the corresponding carbon and phosphorous distribution. The scale bars show concentration of the elements in weight percentage

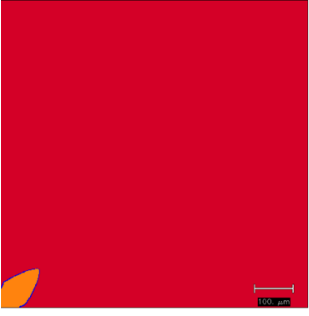

(a) at $1787 \mathrm{~K}$

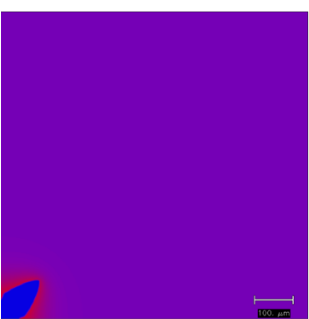

(e) at $1787 \mathrm{~K}$

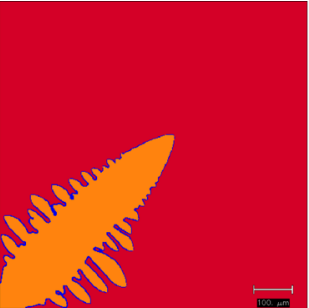

(b) at $1788 \mathrm{~K}$

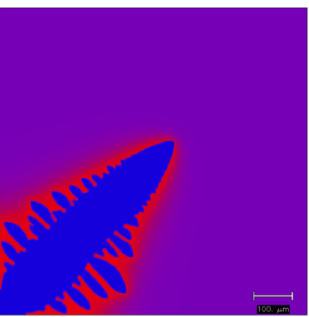

(f) at $1780 \mathrm{~K}$

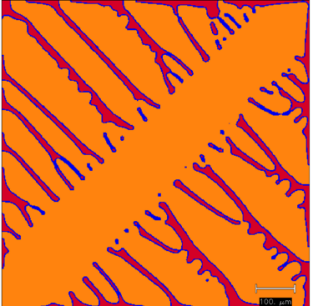

(c) at $1765 \mathrm{~K}$

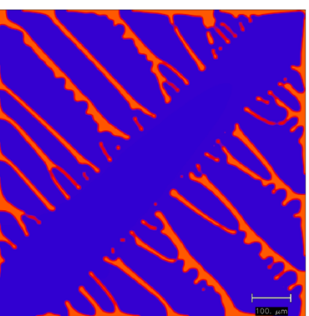

(g) at $1765 \mathrm{~K}$

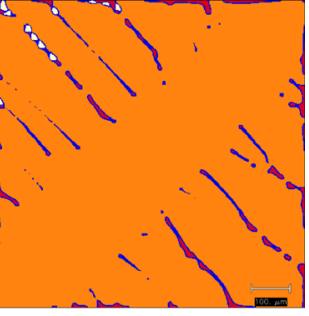

(d) at $1739 \mathrm{~K}$

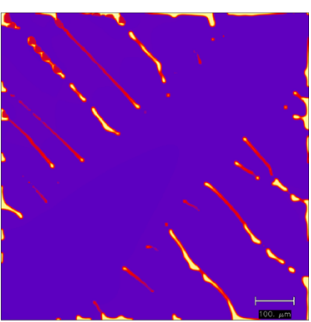

(h) at $1739 \mathrm{~K}$

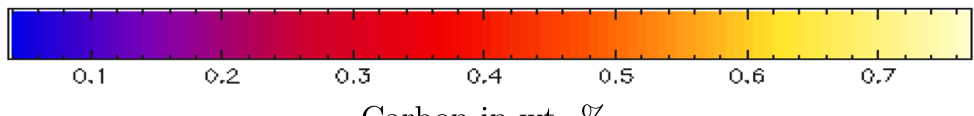

Carbon in wt. $\%$

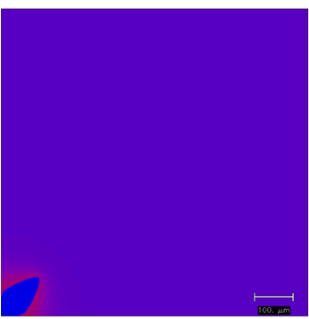

(i) at $1787 \mathrm{~K}$

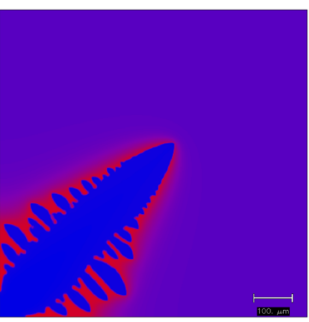

(j) at $1780 \mathrm{~K}$

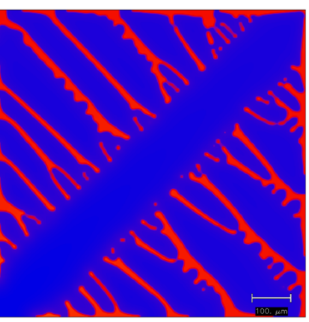

(k) at $1765 \mathrm{~K}$

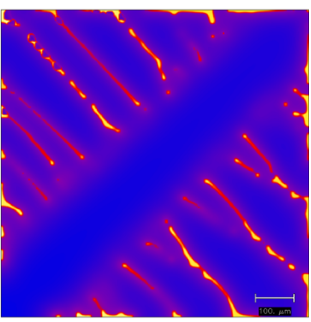

(1) at $1739 \mathrm{~K}$

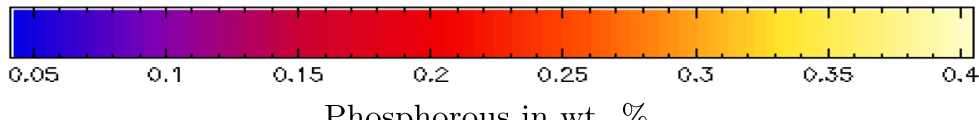

Phosphorous in wt. \%

of boron (27 ppm), the phosphorous content in the liquid decreases in Steel-CPB in comparison with Steel-CP. This effect is demonstrated with the virtual EDS line scans shown in Fig. 8. In the final stages of solidification (at $1771 \mathrm{~K}$ ), phosphorous reaches as high as $0.4 \mathrm{wt} \%$ in Steel-CP, whereas in Steel-CPB, it remains slightly lower $(\leq 0.32 \mathrm{wt} \%)$.

During the solidification of Steel-2CP, the carbon partitioning to the liquid is strongly influenced by the onset of the peritectic reaction. The liquid initially solidifies with a strong partitioning of carbon and phosphorous from solidified $\delta$-ferrite (Fig. 6). Austenite nucleates from the liquid $/ \delta$-ferrite interface at around $1738 \mathrm{~K}$ while cooling from $1800 \mathrm{~K}$ at $1 \mathrm{~K} \mathrm{~s}^{-1}$. As a results, a local partitioning of carbon and phosphorous is observed between solidifying phases below $1783 \mathrm{~K}$, resulting in reduced segregation in the liquid phase at the final stages of solidification (Fig. 6h, 1).

The experimental elemental analysis carried out using EPMA in the fusion zones of resistance spot welds show a clear partitioning of carbon and phosphorous at the grain boundaries of Steel-CP and Steel-CPB. The elemental distribution at the centre of the fusion zones of the spot welds is shown in Fig. 9. The EPMA results clearly indicate that the carbon concentration in the fusion zones of the welds can locally reach as high as $0.4 \mathrm{wt} \%$, for steels with bulk carbon concentrations of $0.07 \mathrm{wt} \%$. The results also show an interesting behaviour in phosphorous segregation while comparing Steel-CP and Steel-CPB. These two steels contain the same amount of carbon and phosphorous but Steel-CPB also contains about $27 \mathrm{ppm}$ of boron. 
Fig. 7 a-d First row shows the evolution of the solidification microstructure of Steel-CPB, during cooling from $1800 \mathrm{~K}$ at a rate of $1 \mathrm{~K} \mathrm{~s}^{-1}$ where the red colour indicates liquid, yellow denotes $\delta$-ferrite and the dendritic boundaries are shown in blue. e-l The second and third row denotes the corresponding carbon and phosphorous distribution. The scale bars show concentration of the elements in weight percentage

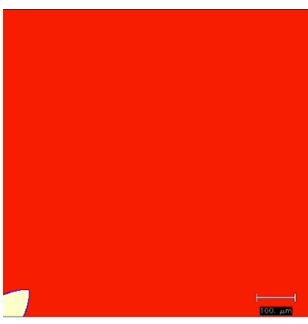

(a) at $1797 \mathrm{~K}$

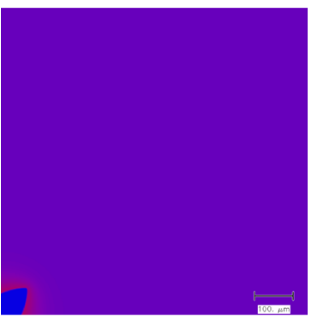

(e) at $1797 \mathrm{~K}$

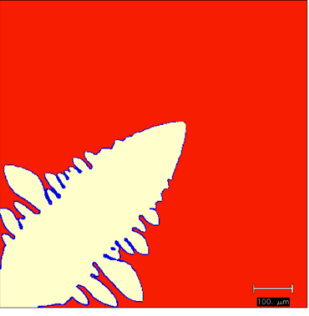

(b) at $1788 \mathrm{~K}$

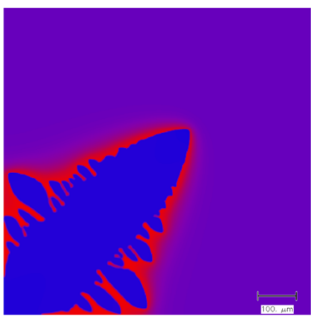

(f) at $1788 \mathrm{~K}$

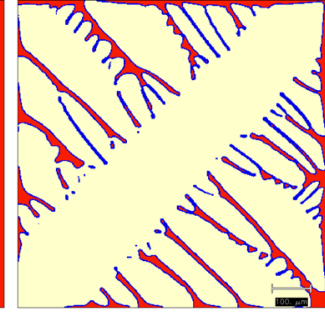

(c) at $1782 \mathrm{~K}$

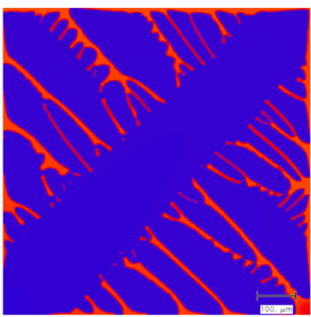

(g) at $1782 \mathrm{~K}$

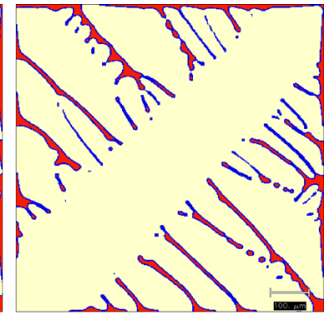

(d) at $1778 \mathrm{~K}$

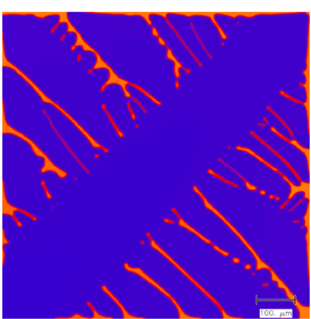

(h) at $1778 \mathrm{~K}$

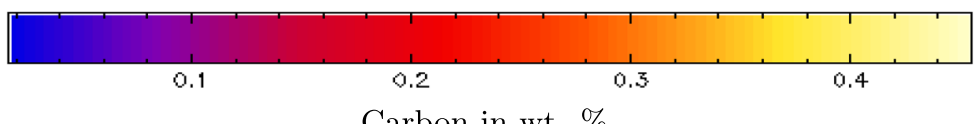

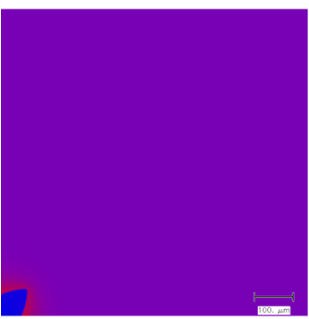

(i) at $1797 \mathrm{~K}$

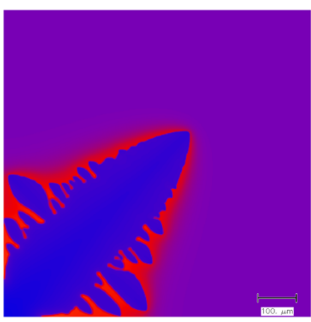

(j) at $1788 \mathrm{~K}$

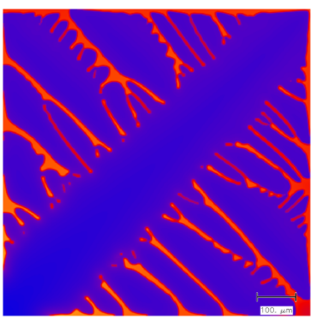

(k) at $1782 \mathrm{~K}$

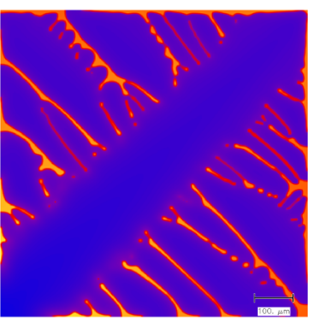

(1) at $1778 \mathrm{~K}$

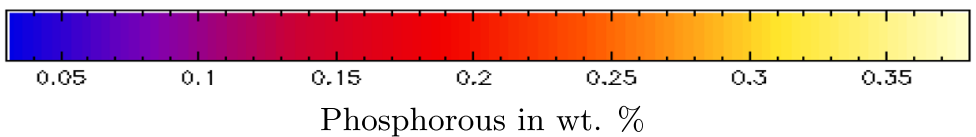

EPMA analysis indicates that the segregation of phosphorous in Steel-CP is higher $(0.3 \mathrm{wt} \%)$ than that of Steel-CPB (Fig. 9a). The local variation of phosphorous in Steel-CPB is found to be less than $0.25 \mathrm{wt} \%$ (Fig. 9b). The phase field simulation also showed that addition of boron reduces the phosphorous segregation to the dendrite boundaries (Fig. 8) and EPMA analysis confirms this finding.

\subsection{Influence of elemental segregation on the mechanical properties of the welds}

The microstructures of the resistance spot-welded samples primarily contain martensite in the fusion zones, after welding using the parameters given in Table 2. Figure 10 shows an overview of the fusion zones of the welds (all at $4 \sqrt{t}$ weld nugget diameters). Mechanical properties of resistance spot-welded Steel-CP and Steel-2CP were evaluated using a tensile peel test (LTS), cross tension tests (CTS) and Vickers hardness measurements. The results were compared with Steel-CPB to study the influence of carbon and boron on the mechanical properties of the welds.

The hardness variation across the width of the welds is shown in Fig. 11. Steel-2CP showed a high hardness in the weld compared to Steel-CP and Steel-CPB due to the presence of a higher amounts of carbon. However, with the same carbon content, the Steel-CPB weld had a slightly higher hardness than Steel-CP weld.

The weld growth curves obtained from tensile peel specimens (Fig. 1a) are shown in Fig. 12. The evolution of the weld nugget diameter with respect to the weld current is 
Fig. 8 a-d Virtual EDS line scans show that concentration of phosphorous in liquid decreases with the addition of boron (Steel-CPB) at the final stages of solidification

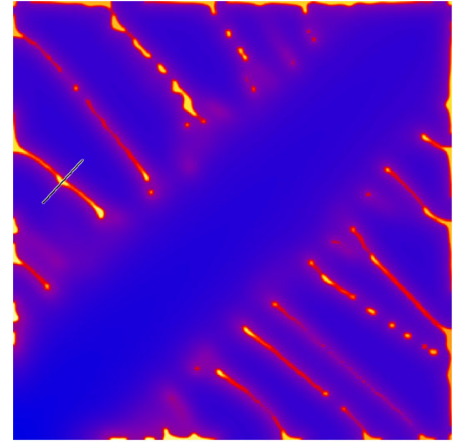

(a) P in Steel-CP at $1771 \mathrm{~K}$

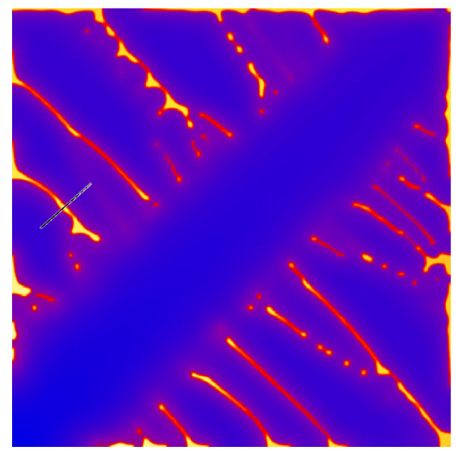

(c) P in Steel-CPB at $1771 \mathrm{~K}$

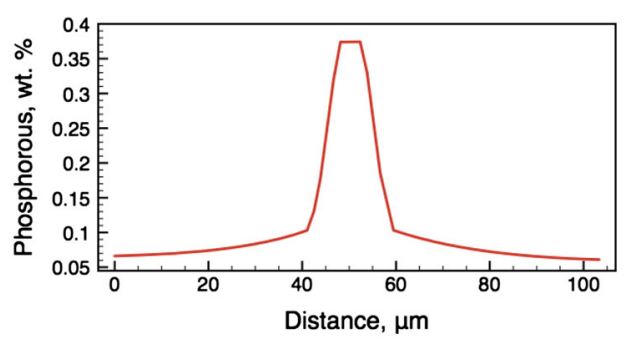

(b) Virtual EDS linescan

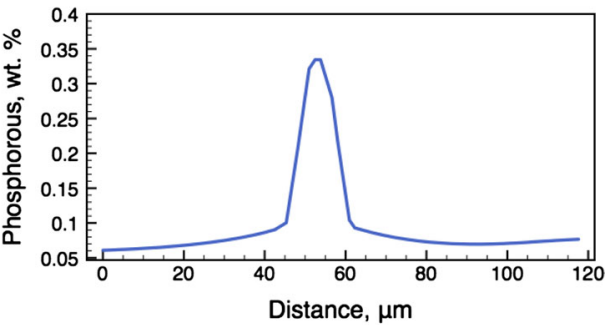

(d) Virtual EDS linescan

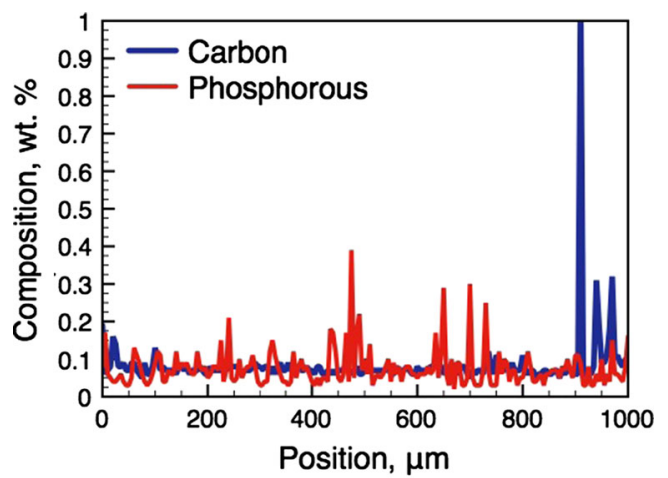

(a) Steel-CP

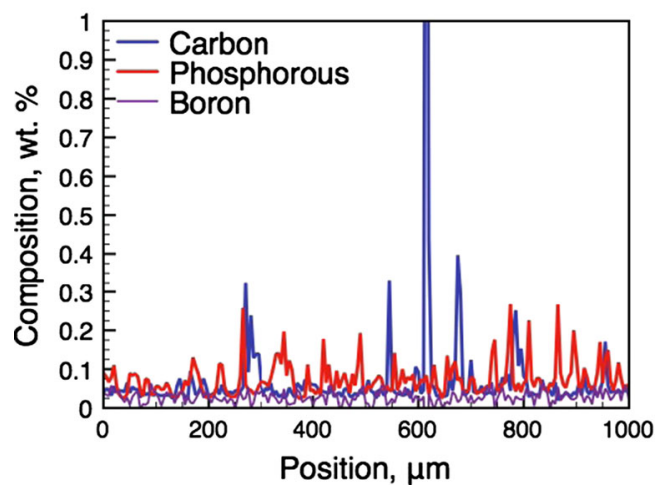

(b) Steel-CPB

Fig. 9 a, b EPMA analysis indicates that addition of boron (Steel$\mathrm{CPB}$ ) reduces phosphorous segregation in the grain boundaries of weld centre line shown in Fig. 12a. It can be seen that the growth curves overlap for all three steels under investigation. Figure $12 \mathrm{~b}$ shows the plug ratio of the welds after the tensile peel test. Steel-2CP shows full interface failures (a plug ratio of $0 \%$ ) during the entire range of testing. Steel-CP shows partial plug failures, with a plug ratio between 30 and $50 \%$. However, with an addition of boron, Steel-CPB predominantly shows a higher plug ratio (70 to $100 \%$ ).

Table 5 shows the weld nugget diameters for the welds made at $\mathrm{I}(\max )$ and their tensile peel strengths obtained from the tensile peel tests. Welds of Steel-CPB exhibit a better tensile behaviour than Steel-CP and Steel-2CP welds. The weld nugget diameter of Steel-CPB is larger $(8.1 \mathrm{~mm})$ than for the welds of Steel-CP and Steel-2CP $(6.8$ and $6.6 \mathrm{~mm}$, respectively). Moreover, the tensile peel tests resulted in weld metal failure for Steel-CP and Steel-2CP. The welds of Steel-CPB show a full plug failure, which is an acceptable failure mode for the spot welds, thereby exhibiting improved mechanical properties compared to welds of Steel-CP and Steel-2CP (Fig. 13).

The influence of the composition and the weld nugget diameters on the cross tension strength is shown in Fig. 14. The plug ratio after the cross tension testing is also indicated for each welds in Fig. 14. The failure modes and plug ratio of the cross tension samples are in line with those obtained with the tensile peel samples. Steel-2CP shows full interface failures (plug ratio of $0 \%$ ), resulting in a low CTS strength. Steel-CP and Steel-CPB both show partial plug failures. 


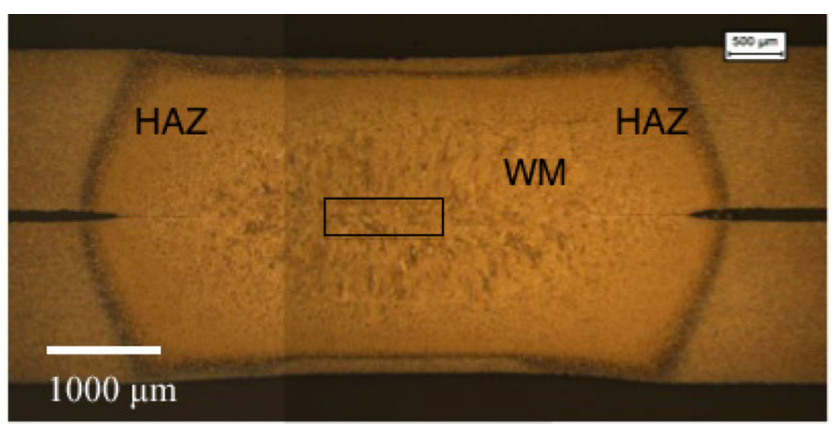

(a) Steel-CP

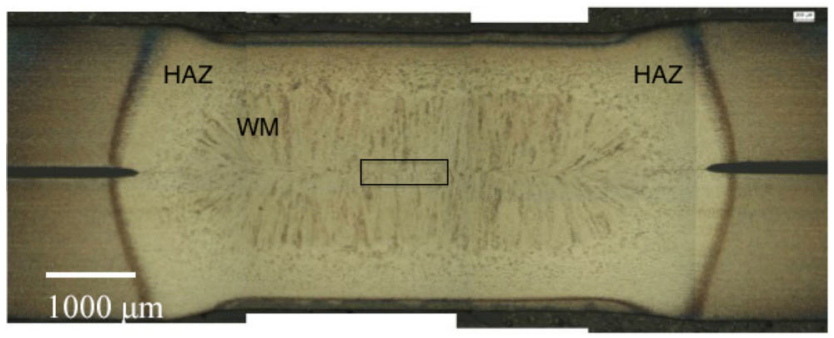

(b) Steel-2CP

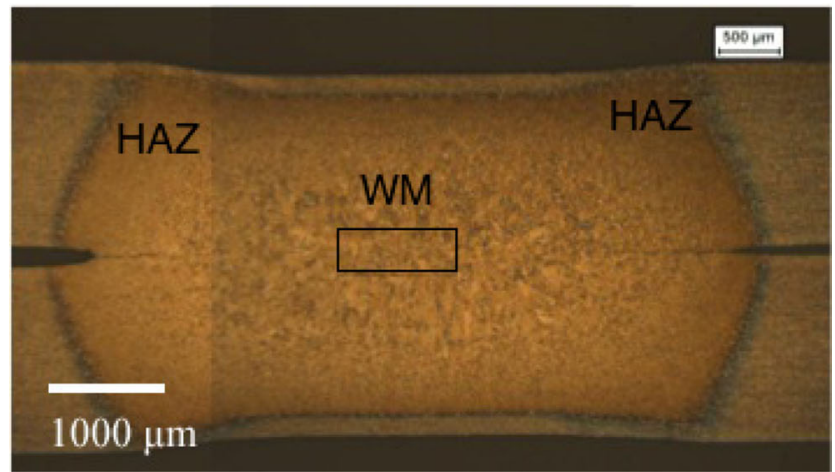

(c) Steel-CPB

Fig. 10 a-c Overview of the resistance spot welds, where $W M$ is weld metal and $H A Z$ is heat-affected zone. The black box indicates the area where EPMA measurements were carried out. Welds were made at I(min) (see Table 2)

The cross tension strength of Steel-CPB welds is in general higher than that of Steel-CP welds. Moreover, the plug ratio for the Steel-CPB welds is also higher (81\%) than Steel-CP welds.

Despite containing a similar carbon concentration, it can clearly be seen that the boron added Steel-CPB welds show a significant increase in strength and failure behaviour as compared with Steel-CP.

\section{Discussions}

The partitioning behaviour of alloying elements during resistance spot welding has been studied in steels. Quasi-binary phase diagrams of these steels (Fig. 2) show

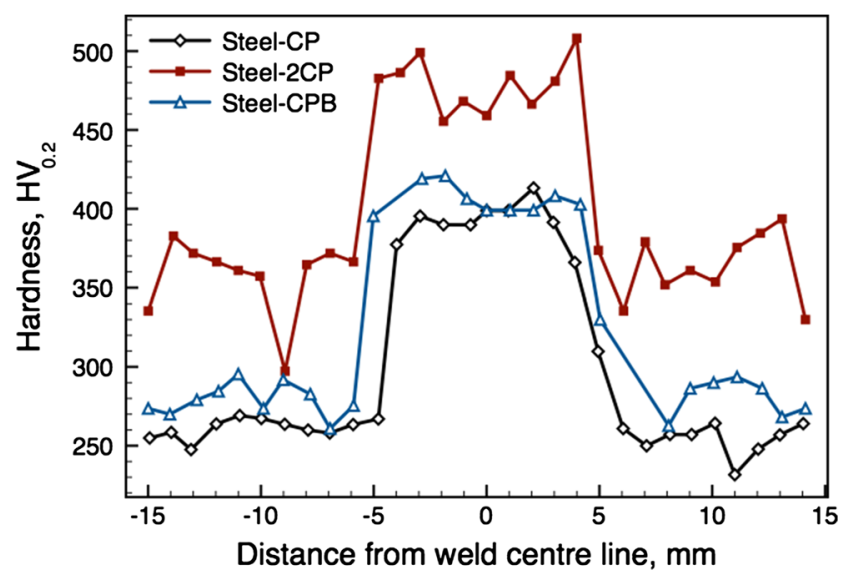

Fig. 11 Hardness variation across the width of the welds. Welds were made at $\mathrm{I}(\mathrm{min})$ (see Table 2)

that Steel-CP and Steel-CPB completely solidifies to $\delta$ ferrite from liquid, whereas in Steel-2CP, austenite forms from liquid $/ \delta$-ferrite by a peritectic reaction starting from $1765 \mathrm{~K}$ under equilibrium conditions. In steels, segregation of alloying elements begins from the onset of solidification due to the difference in solubility of alloying elements between liquid, $\delta$-ferrite and austenite. Thus, it is important to compare the solidification behaviour of Steel-CP and Steel-2CP to understand the influence of the peritectic reaction on the partitioning behaviour of phosphorous.

The solidification kinetics calculated from the phase field-based solidification model indicates that with increasing carbon content, time for complete solidification also increases when cooling from $1800 \mathrm{~K}$ (Fig. 3). In a typical resistance spot weld thermal cycle, the rate at which the weld pool is cooled can be as high as $2000 \mathrm{~K} \mathrm{~s}^{-1}$ [34]. With sufficient undercooling and fast cooling rates in practical welding conditions, it is even possible for the liquid to directly solidify to austenite as a primary solidification phase [35]. The phase field simulation also showed that with a cooling rate $1 \mathrm{~K} \mathrm{~s}^{-1}$, the onset of peritectic reaction is found at $1738 \mathrm{~K}$ for Steel-2CP while Steel-CP and Steel$\mathrm{CPB}$ did not show any peritectic reaction before the completion of solidification. Even after an enrichment of carbon of about $0.4 \mathrm{wt} \%$ at the final stages of solidification in Steel$\mathrm{CP}$ and Steel-CPB, formation of non-equilibrium austenite is not found at the liquid/ $\delta$-ferrite interfaces (Figs. 5 and 7).

The phase field modelling of solidification showed the effect of the bulk concentration and the onset of the peritectic reaction on the elemental partitioning between the liquid and the solidifying phases. In both Steel-CP and Steel-CPB, just before the completion of solidification, the liquid contained about $0.4 \mathrm{wt} \%$ of carbon. For the steels with bulk carbon content of $0.07 \mathrm{wt} \%$, this segregation of carbon is crucial in determining the mechanical properties of the weld, as it may lead to the formation of brittle carbides 
Fig. 12 a, b Weld growth curves generated using the tensile peel samples shown in Fig. 1a

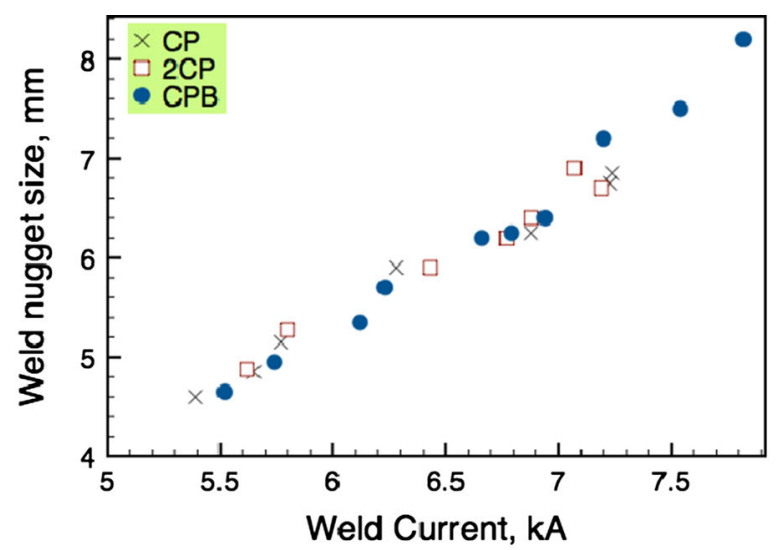

(a) Evolution of weld diameter as a funcion of weld current

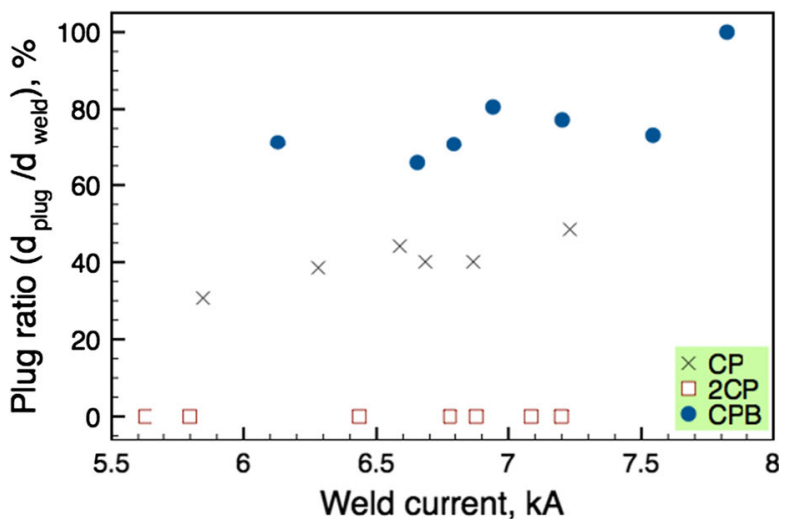

(b) Plug ratio (the ratio of plug diameter after tensile peel test with the weld diameter) as a function of weld current at the inter-dendritic boundaries. The EPMA measurement carried out in the centre of the fusion zones of resistant spot-welded samples also confirms partitioning behaviour of carbon (Fig. 9). Carbon concentration at the grain boundaries was found to vary from 0.3 to $0.4 \mathrm{wt} \%$. The carbon peak, showing more than $1 \mathrm{wt} \%$, is due to the presence of iron carbide at a grain boundary. Simulation results indicate that the onset of the peritectic reaction trigger local partitioning of carbon to the newly formed austenite from the $\delta$-ferrite (Fig. 6). As the solubility of carbon in austenite is higher than in $\delta$-ferrite, carbon partitions to austenite and thereby reduces the amount of carbon that diffuses to the unsolidified liquid (Fig. 6).

Table 5 Weld nugget diameters and tensile peel strengths of resistance spot welds at I(max). (See Table 2 for welding parameters)

\begin{tabular}{lll}
\hline Steel & Weld nugget diameter, mm & Tensile peel strength, kN \\
\hline Steel-CP & 6.8 & 1.6 \\
Steel-2CP & 6.6 & 1.0 \\
Steel-CPB & 8.1 & 3.9 \\
\hline
\end{tabular}

The embrittlement of welds resulting from the segregation of phosphorous to grain boundaries is reported to be reduced due to the addition of boron $[13,15]$. EPMA analysis indicated that with an addition of $27 \mathrm{ppm}$ of boron, the phosphorous segregation at the grain boundaries in the fusion zone of Steel-CPB was reduced considerably. About 0.35 to $0.4 \mathrm{wt} \%$ phosphorous was found in some grain boundary areas in the fusion zone of Steel-CP (Fig. 9a), whereas in Steel-CPB, the phosphorous segregation at the grain boundaries was less than $0.25 \mathrm{wt} \%$ (Fig. 9b). This decrease due to the addition of boron is also observed in phase field simulations (Fig. 8). The addition of boron is known to suppress the segregation of phosphorous at the grain boundaries. It is reported that due to the faster diffusion of boron than phosphorous atoms in the iron matrix, boron segregates at the grain boundaries much earlier than phosphorous. The presence of boron atoms at the grain boundaries may lead to the subsequent retardation of phosphorous diffusion $[8,12]$, thereby reducing the grain boundary segregation.

The mechanical properties of the resistance spot welds reflected the effect of composition and the microstructure. 
Fig. 13 a-f Failure surfaces of welds after tensile peel testing, showing that boron addition improves the mechanical properties. Welds were made at $\mathrm{I}(\max )$ (see Table 2)

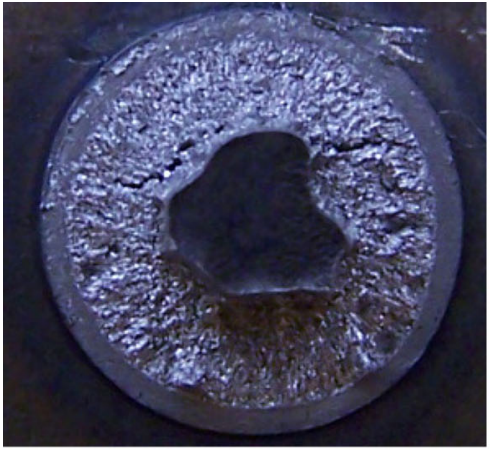

(a) Steel-CP weld after testing

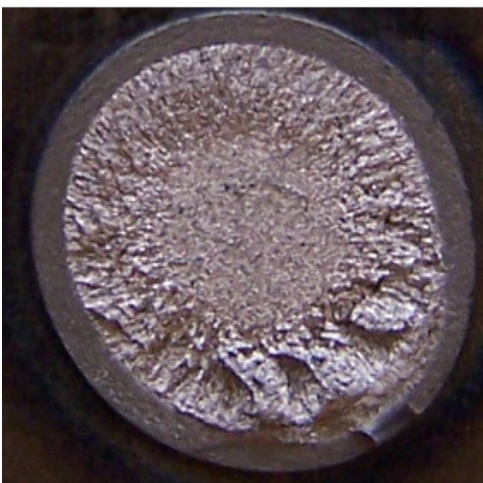

(c) Steel-2CP weld after testing

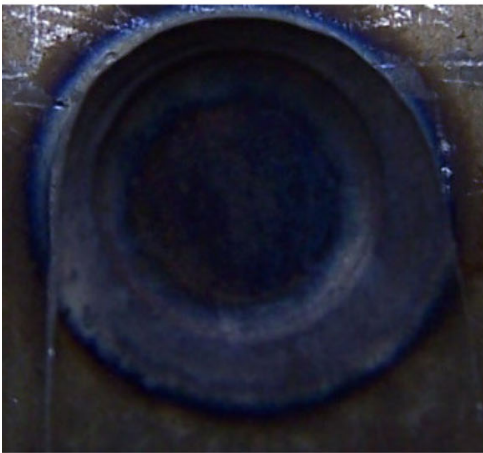

(e) Steel-CPB weld after testing

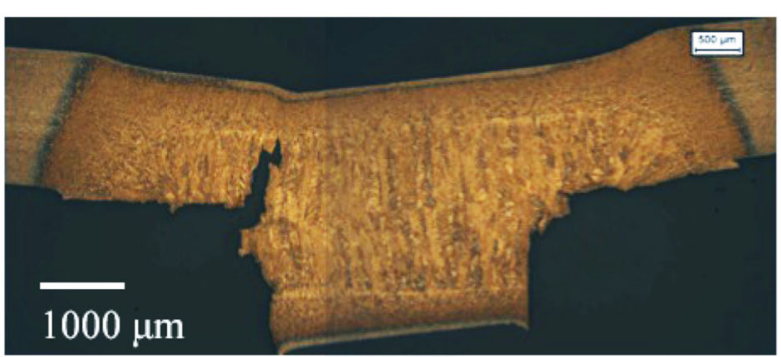

(b) Cross section indicates a partial plug failure.

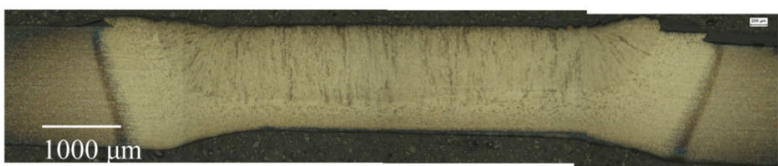

(d) Cross section indicating a complete interface failure.

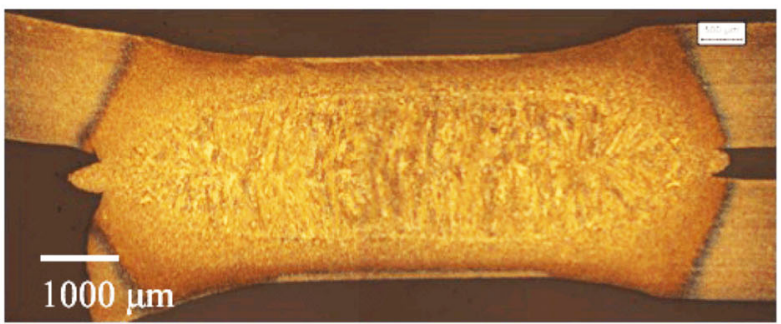

(f) Cross section indicating that weld is in-tact.
The weld zones of Steel-2CP showed a higher hardness than Steel-CP and Steel-CPB due to the presence of more carbon (Fig. 11). With the same carbon content, the weld of SteelCPB showed a slightly higher hardness than Steel-CP due to the presence of boron. An earlier study indicates that in presence of boron, an increased amount of martensite was found in Steel-CPB in comparison with Steel-CP. This leads to an increase in the hardness of the weld zone of Steel-CPB [36].

The addition of boron to steel also significantly increased the cross tension strength of the welds (Fig. 14). The CTS strength at $6 \mathrm{~mm}$ weld diameter increased from $3.5 \mathrm{kN}$ for Steel-CP to aproximately $5.5 \mathrm{kN}$ for Steel-CPB. Apart from an increase in strength, the failure mode of boron-added Steel-CPB was found to improve significantly as compared with Steel-CP and Steel-2CP (Figs. 12a and 13).

During tensile peel testing at I(max), the weld of SteelCPB did not fail and a failure was observed in the HAZ. By contrast, in welds of Steel-CP and Steel-2CP, cracks were found to initiate at the fayed interfaces and propagated along the grain boundaries at the centre of the fusion zone. The results of the cross tension tests show that with an addition of $27 \mathrm{ppm}$ of boron, the mechanical properties of the welds significantly improved compared with steels containing no boron. In Steel-CP and Steel-2CP, the presence of high amounts of phosphorous and carbon at the 


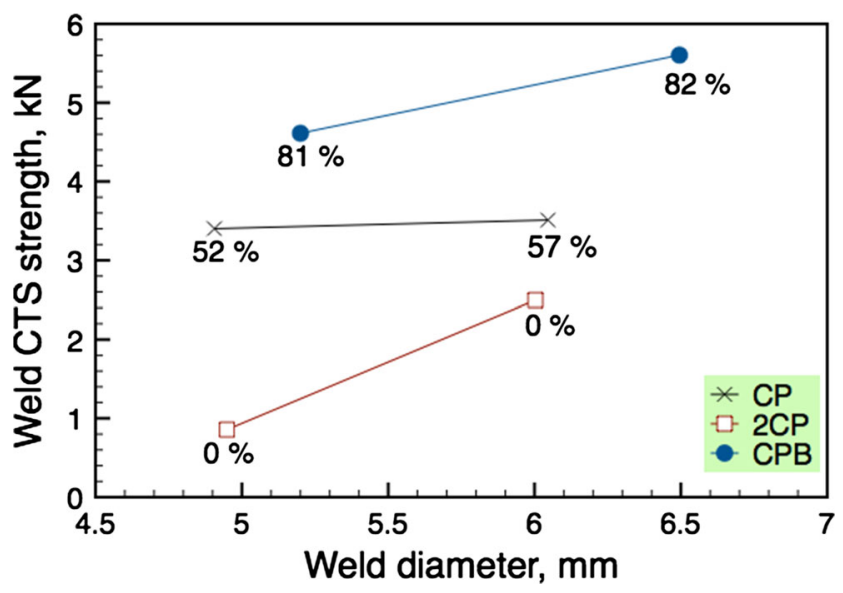

Fig. 14 Cross tension strength (CTS) as a function of weld diameters for the steel welds under investigation. Plug ratio (\%) after the cross tension test is also mentioned for each condition

grain boundaries led to the deterioration of the mechanical properties of the weld. As the EPMA measurement and phase field simulation show, the addition of boron significantly reduces the segregation of phosphorous at the grain boundaries and the mechanical properties of the welds in the boron-added Steel-CPB is better than those of Steel-CP and Steel-2CP.

\section{Conclusions}

Elemental segregation studies during welding of phosphorous- and boron-containing steels were carried out in this work by experiment and phase field-based solidification models. The results reported lead to the following conclusions:

1. The onset of the solidification of the weld pool reduced from $1796 \mathrm{~K}$ (for Steel-CP and Steel-CPB) to $1787 \mathrm{~K}$ with an increase in carbon content (Steel-2CP). For a steel with higher carbon content, solidification completes at low temperature $(1758 \mathrm{~K})$ than for a steel with a low carbon content (at $1764 \mathrm{~K}$ ).

2. The solidification of the weld pool progresses with a strong partitioning of carbon and phosphorous to the unsolidified liquid. For steels with $0.07 \mathrm{wt} \%$ of bulk carbon, at the end of solidification, the carbon concentration in the liquid can reach as high as $0.4 \mathrm{wt} \%$. Similarly, phosphorous in the unsolidified liquid can be about $0.4 \mathrm{wt} \%$ for steels with bulk phosphorous of $0.08 \mathrm{wt} \%$.

3. The onset of the peritectic reaction during solidification can significantly change the partitioning behaviour of the alloying elements due to the local partitioning between the solidifying austenite and $\delta$-ferrite.
4. Addition of boron increases the hardness of the welds due to the possible increase of martensite volume fraction in the heat affected zones for the steels with a similar carbon concentration.

5. With an acceptable failure mode, tensile peel and cross tension strengths of steel welds are improved with the addition of boron. Boron was found to suppress the grain boundary segregation of phosphorous, thereby reducing the embrittlement of the welds.

Acknowledgments This research was carried out under Project No. MC8.04188 in the framework of the Research Program of the Materials Innovation Institute M2i (www.m2i.nl), the former Netherlands Institute for Metals Research and FOM-M2i IPP programme "Physics of Failure" project number 13POF05 (M2i - F22.8.13485b). The authors also thank Tata Steel for providing access to welding and mechanical testing facilities.

Open Access This article is distributed under the terms of the Creative Commons Attribution 4.0 International License (http:// creativecommons.org/licenses/by/4.0/), which permits unrestricted use, distribution, and reproduction in any medium, provided you give appropriate credit to the original author(s) and the source, provide a link to the Creative Commons license, and indicate if changes were made.

\section{References}

1. Keeler S (2009) Advanced high strength steels (AHSS) guidelines. Technical Report Version 4.1, World auto steel, World steel association

2. Amirthalingam M, Hermans MJM, Richardson IM (2009) Microstructural evolution during welding of transformation induced plasticity steels-inclusion and elemental partitioning analysis. Metall Mater Trans A 40A:901-909

3. Chen HC, Era H, Shimizu M (1989) Effect of phosphorous on the formation of retained austenite and mechanical properties in si-containing low carbon steel sheet. Metall Trans A 20A:437-445

4. De Cooman BC (2004) Structure-properties relationship in TRIP steels containing carbide-free bainite. Curr Opinion Solid State Mater Sci 8:285-303

5. Mahieu J, Claessens S, De Cooman BC (2001) Galvanisability of high-strength steels for automotive applications. Metall Mater Trans A 32A:2905-2907

6. Maki J, Mahieu J, De Cooman BC, Claessens S (2003) Galvanisability of silicon free $\mathrm{CMnAl}$ trip steels. Mater Sci Technol 19:125-131

7. Yuasa M, Mabuchi M (2012) Grain boundary embrittlement of Fe induced by p segregation: first-principles tensile tests. Adv Mater Res 409:455-460

8. Wu R, Freeman AJ, Olson GB (1994) First principles determination of the effects of phosphorus and boron on iron grain boundary cohesion. Science 265:376-380

9. Wang J, van der Zwaag S (2001) Stablisation mechanisms of retained austenite in transformation-induced plasticity steels. Metall Mater Trans A 31A:1527-1539

10. Zhao Z, Mao W, Yu Y (2000) Precipitatation behavior of FeTiP phase in high strength IF steel. J Univ Sci Technol Beijing Miner Metall Mater (Eng Ed) 7:197-203 
11. Joshi A (1975) Segregation at selective grain boundaries and its role in temper embrittlement of low alloy steels. Scripta Metall 9:251-260

12. Paju M, Möller R (1984) The effect of boron on phosphorus segregation in austenite. Scripta Metallurgica 18:813-815

13. Chen W, Chaturvedi MC, Richards NL (2001) Effect of boron segregation at grain boundaries on heat-affected zone cracking in wrought INCONEL 718. Metall Mater Trans A Phys Metall Mater Sci 32:931-939

14. Babu SS, Goodwin GM, Rohde RJ, Sielen B (1998) Effect of boron on the microstructure of low-carbon steel resistance seam welds, vol 77, pp 249-s

15. Jung J-G, Kim J, Noh K-M, Park KK, Lee Y-K (2012) Effects of $\mathrm{b}$ on microstructure and hardenability of resistance seam welded HSLA linepipe steel. Sci Technol Weld Join 17:77-84

16. Zhang D, Shintaku Y, Suzuki S, Komizo Y-I (2012) In situ observation of phase transformation in low-carbon, boron-treated steels. Metall Mater Trans A: Phys Metall Mater Sci 43:447-458

17. Koganti R, Angotti S, Cooper R, Houston D, Waheed A, Topper, TH (2009) Material characterization of uncoated boron steel for automotive body structure applications. In: Proceedings of the ASME International Manufacturing Science and Engineering Conference, MSEC2008, vol 2, pp 149-154

18. Lee HE, Kim YH, Lee SK, Lee KH, Park JU, Sung JH (2007) Effect of boron contents on weldability in high strength steels. J Mech Sci Technol 21:771-777

19. Thiessen RG, Richardson IM (2006a) A physically based model for microstructure development in a macroscopic heat-affected zone: grain growth and recrystallisation. Metall Mater Trans B 37B:655-663

20. Thiessen RG, Richardson IM (2006b) A strategy for modeling microstructure in macroscopic simulations of welded material. Metall Mater Trans B 37B:293-299

21. Mecozzi MG, Sietsma J, van der Zwaag S, Apel M, Schaffnit P, Steinbach I (2005) Analysis of $\gamma \rightarrow \alpha$ transformation in a C-Mn steel by phase field modelling. Metall Mater Trans A 36A:23272340

22. Mecozzi MG, Sietsma J, van der Zwaag S (2006) Analysis of $\gamma \rightarrow$ $\alpha$ transformation in a $\mathrm{Nb}$ micro-alloyed C-Mn steel by phase field modelling. Acta Materialia 54:1431-1440

23. Rao W-F, Khachaturyan AG (2011) Phase field theory of proper displacive phase transformations: structural anisotropy and directional flexibility, a vector model, and the transformation kinetics. Acta Materialia 59:4494-4503
24. Wang Y, Khachaturyan AG (2006) Multi-scale phase field approach to martensitic transformations. Mater Sci Eng A 438440:55-63

25. Karma A, Rappel W-J (1998) Quantitative phase-field modeling of dendritic growth in two and three dimensions. Phys Rev E Stat Phys Plasmas Fluids Relat Interdiscip Topics 57:43234349

26. Bi Z, Sekerka RF (1998) Phase-field model of solidification of a binary alloy. Physica A: Stat Mech Appl 261:95-106

27. Boettinger WJ, Warren JA, Beckermann C, Karma A (2002) Phase-field simulation of solidification. Annu Rev Mater Sci 32:163-194

28. Steinbach I, Pezzolla F, Nestler B, Seesselberg M, Prieler R, Schmitz GJ (1996) A phase field concept for multiphase systems. Physica D 94:135-147

29. Steinbach I, Pezzolla F (1999) A generalised phase field method for multiphase transformation using interface fields. Physica D 134:385-393

30. Böttger B, Stratemeier S, Subasic E, Göhler K, Steinbach I, Senk D (2010) Modelling of hot ductility during solidification of steel grades in continuous casting - part ii. Adv Eng Mater 12:101109

31. Hofmann H, Mattissen D, Schaumann TW (2009) Advanced cold rolled steels for automotive applications. Steel Res Int 80: 22-28

32. SEP 1220-2 (2007) Testing and documentation guideline for the joinability of thin sheet of steel-part 2: resistance spot welding. Technical Report 08, VDEh standard

33. Armstrong JT (1991) Quantitative elemental analysis of individual microparticles with electron beam instruments. In: Heinrich KFJ, Newbury DE, Armstrong JT (eds) Electron probe quantitation. Plenum press, pp 261-315

34. den Uijl NJ (2007) Post weld heat treatments of advanced high strength steel for automotive joining. Math Model Weld Phenom 8:217-223

35. Babu SS, Elmer JW, Vitek JM, David SA (2002) Time-resolved $\mathrm{x}$-ray diffraction investigation of primary weld solidification in $\mathrm{Fe}$ C-Al-Mn steel welds. Acta Materialia 50:4763-4781

36. Amirthalingam M, van der Aa EM, den Uijl NJ, Hermans MJM, Richardson IM (2013) Phosphorous and boron segregation during resistance spot welding of advanced high strength steels. In: Trends in welding research. ASM International, pp 217226 